\title{
Anatomia e morfometria de raízes e folhas de Urochloa brizantha cv. Marandu em diferentes estádios de acometimento da síndrome da morte das pastagens ${ }^{1}$
}

\author{
Norberto Gomes Ribeiro Júnior, Ivone Vieira da Silva, \\ Cleonete Ferreira de Araújo, Odair de Souza Fagundes \& Wagner Gervazio
}

\begin{abstract}
Universidade do Estado de Mato Grosso, Faculdade de Ciências Biológicas e Agrárias, Laboratório de Biologia Vegetal, Av. Perimetral Rogério Silva, 4930, Flamboyant, CEP 78580-000, Alta Floresta, Mato Grosso, Brasil. biologo_norbertojunior@hotmail.com

' Parte da dissertação de mestrado do primeiro autor no Programa de Pós-graduação em Biodiversidade e Agroecossistemas Amazônicos
\end{abstract}

Recebido em 27.X. 2015

Aceito em 29.IV.2017

DOI: 10.21826/2446-8231201772111

RESUMO - Este estudo descreve as alterações teciduais em indivíduos de Urochloa brizantha cv. Marandu de populações sob acometimento da síndrome da morte das pastagens (SMP). Foram coletados indivíduos em três estádios morfológicos distintos, em uma propriedade rural da Amazônia Meridional, no norte de Mato Grosso. Lâminas histológicas foram montadas a partir de secções do terço médio de raízes e das folhas, nelas foram avaliadas as proporções e características dos tecidos em indivíduos saudáveis e comparadas com indivíduos em estádio intermediário e estádio mais avançado da SMP. Nas raízes, foi observada diminuição do espessamento das paredes celulares da exoderme e endoderme, crescente desorganização das células corticais, lise celular no floema e medula parenquimática. Nas folhas, ocorreu diminuição de tricomas, aumento do tamanho das células buliformes, diminuição de fibras e do mesofilo na nervura central. Aparentemente, a SMP provocou as primeiras alterações nas raízes, dificultando o fluxo de substâncias e o funcionamento dos tecidos.

Palavras-chave: morte súbita, forrageira, degradação, lise celular

ABSTRACT - Urochloa brizantha cv. Marandu root and leaf morphometry at different stages of involvement of the death of pastures syndrome. This study describes the tissue changes in Urochloa brizantha cv. Marandu from populations under death of pastures syndrome (DPS). The individuals were collected in three distinct morphological stages in a farm in the southern region of the Amazon in northern Mato Grosso. Histological slides were made from sections of the middle third of the roots and leaves, and the proportions and characteristics of tissues in healthy individuals were evaluated and compared with individuals in middle stage and later stage of the DPS. Roots gradually decreased the thickening of the cell walls of exoderm and endoderm, and growing disorganization of the cortex and cell lysis in the phloem and parenchyma pith were observed. Trichomes on leaves decreased, an increase of the volume of buliforme epidermal cells, a decrease of fibers and of the mesophyll midrib. Apparently, DPS causded the first changes in the roots hindering the flow of substances and of tissue function.

Keywords: sudden death, forage, degradation, cell lysis

\section{INTRODUÇÃO}

No Brasil, diversas áreas utilizadas para a bovinocultura apresentam algum grau de degradação, devido à falta de reposição de nutrientes, manejo inadequado e sobrecarga de unidade animal (UA) por hectare. Para determinados graus de degradação, a única solução apontada por muitos especialistas é a "reforma das pastagens", descompactando o solo, realizando a correção destas através de calagem e cultivando novas espécies de capim (Da Silva 2007).

O gênero Urochloa P. Beauv. (Poaceae) compreende aproximadamente 200 espécies. Destas, algumas são importantes forrageiras muito utilizadas em regiões tropicais. Dentre as várias espécies utilizadas, Urochloa brizantha (Hochst. ex A. Rich.) R. D. Webster se tornou a mais relevante do gênero no Brasil, destacando-se a cultivar Marandu, que foi amplamente difundida a partir de sua liberação para comércio pela Empresa Brasileira de Pesquisa Agropecuária (EMBRAPA) em 1984, devido principalmente à sua alta produtividade (Soares et al. 2009).

Desde meados da década de 1990, há relatos de focos de morte do capim Marandu. Estes surgem em áreas específicas da pastagem, as chamadas reboleiras, sobretudo em regiões dos pastos onde ocorre acúmulo de água no período de chuvas (Dias-Filho 2006).

Silva et al. (2005) relatam que indivíduos expostos a situações ambientais adversas, como alterações de intensidade de luz, podem ter as quantidades de tecido fotossintético (parênquima clorofiliano) alteradas; se o solo apresentar alta concentração de alguns íons como alumínio, boro ou mesmo nitrogênio podem ocorrer disfunções metabólicas e até lise de tecidos; e o estrese hídrico pode gerar aumento de densidade, alteração dos espaços intercelulares e do tamanho do mesofilo.

Objetivou-se nesse trabalho descrever a estrutura anatômica de raízes e folhas de Urochloa brizantha cv. 
Marandu em populações que apresentam diferentes estádios morfológicos, visando conhecer o processo de evolução da síndrome da morte das pastagens nos tecidos.

\section{MATERIAL E MÉTODOS}

Com a ocorrência de muitos casos da síndrome da morte das pastagens (SMP) na região do extremo norte de Mato Grosso, foi realizado um levantamento através de visitas a propriedades rurais, com possíveis pontos de coleta. Posteriormente foi sorteada uma propriedade, localizada nas coordenadas $10^{\circ} 01^{\prime} 22^{\prime \prime} \mathrm{S}$ e $56^{\circ} 11^{\prime} 02^{\prime \prime} \mathrm{W}$, para coleta do material vegetal (Urochloa brizantha cv. Marandu).

A região integra a depressão amazônica sulamericana, com clima equatorial continental úmido e estação seca de maio a setembro. $\mathrm{O}$ índice pluviométrico anual pode exceder $2.300 \mathrm{~mm}$ e a temperatura média anual é de 24,8 ${ }^{\circ} \mathrm{C}$ (SEPLAN 2006).

A área de coleta localiza-se no município de Alta Floresta, MT, uma propriedade rural com aproximadamente 200 hectares, com práticas de pecuária extensiva de gado de corte, onde $U$. brizantha foi implantada há aproximadamente 14 anos.

As regiões onde ocorreram a SMP se apresentavam de diferentes formas. Para as coletas buscou-se um padrão de reboleira de diâmetro inferior a 3 metros, onde foram identificadas touceiras em estádios morfológicos distintos. Procedeu-se então as coletas obedecendo a três parâmetros: 1. Indivíduos aparentemente saudáveis localizados às margens das reboleiras; 2. Indivíduos que apresentam sintomas iniciais da SMP com folhas amareladas presentes na região limite da reboleira; 3 . Indivíduos em estádio final da SMP, localizados no centro das reboleiras.

Com o auxílio de enxada, foram obtidas doze touceiras de $U$. brizantha por reboleira, sendo quatro em cada um dos estádios morfológicos. Da parte inferior da touceira, foram cortadas as raízes de maior diâmetro e dos perfilhos foram retiradas a segunda folha a partir da base. Para obter um número amostral significativo, foram realizadas coletas de material vegetal em três reboleiras, com no mínimo 50 metros de distância entre elas.

Em seguida, o material coletado passou pelo processo de fixação em FAA 50 (formaldeído, ácido acético glacial e etanol 50\% 5:5:90, v/v) em campo. No Laboratório de Biologia Vegetal da Universidade do Estado de Mato Grosso - Alta Floresta foram mantidas por 48 horas em bomba a vácuo e posteriormente estocadas em álcool etílico a 70\% (Johansen 1940).

De cada touceira foram utilizadas duas raízes e duas folhas, constituindo duas repetições. Amostras da região localizada no terço médio das raízes e a região mediana das folhas foram analisadas anatomicamente. Cortes transversais foram obtidos à mão livre, com lâmina de barbear e corados em dupla coloração, azul de astra e fucsina básica (Roeser 1962), e posteriormente montados em lâminas histológicas semi-permanentes com gelatina glicerinada.
As amostras foram analisadas em microscópio fotônico trinocular Leica ${ }^{\circledR}$ ICC50 acoplado a um computador, sendo registradas fotomicrografias com auxílio do software LAZ EZ 1.7.0, onde foram avaliados caracteres anatômicos quantitativos e qualitativos. Foram aferidos quantitativamente:1) diâmetro da raiz; 2) espessura da epiderme da raiz; 3 ) número de polos de protoxilema; 4) diâmetro do cilindro vascular da raiz; 5) espessura do mesofilo foliar; 6) espessura do grupo de fibras da nervura foliar abaxial; 7) espessura do grupo de fibras da nervura foliar adaxial; 8) espessura da nervura central foliar; 9) tamanho de células buliformes. Foram avaliados qualitativamente: 1) presença de idioblastos; 2) formato de células epidérmicas; 3 ) espessura da cutícula; 4) características da exoderme; 5) forma e tamanho dos tricomas; 6) disposição das células do mesofilo; 7) variações nas fibras extravasculares e vasculares; 8) estrutura dos feixes vasculares.

Para a análise da epiderme, foram selecionadas três folhas de cada touceira, totalizando 36 amostras de cada face da folha. Foi utilizado o método de dissociação de Kraus \& Arduin (1997). Os fragmentos da epiderme foram coradas com fucsina básica, montadas em glicerina e analisados três campos por amostra.

Foram selecionadas aleatoriamente secções transversais de folha e de raiz para a morfometria. As medidas foram inferidas através das imagens no programa Anati Quanti $2^{\circledR}$ UFV (Aguiar et al. 2007), totalizando 72 imagens de folha $\mathrm{e}$ 72 imagens de raízes. Posteriormente, foram comparados os três estádios morfológicos quanto as variáveis quantitativas. Os dados foram submetidos à análise de variância pelo teste $\mathrm{F}$ e as médias foram comparadas pelo teste de Tukey, a 5\% de probabilidade (Ferreira 2011).

\section{RESULTADOS E DISCUSSÃO}

Quando analisadas em campo no momento pré-coleta, Urochloa brizantha cv. Marandu afetados severamente pela síndrome da morte de pastagens (SMP) apresentaram folhas amareladas e/ou secas e porte inferior ao de plantas saudáveis, aparentando características similares aos de indivíduos da espécie expostos a déficit hídrico severo.

Nas raízes, observou-se a presença de grande quantidade de pelos absorventes em todos os estádios da SMP, além do surgimento de raízes laterais nos indivíduos analisados. Os pelos exibiram-se unicelulares com gradativo afilamento ao se distanciar da origem.

Dias-Filho (2006) afirmou que em $U$. brizantha submetida a encharcamento do solo, ocorreu diminuição das raízes e acúmulo de maior quantidade de amido nas folhas, alterando os mecanismos de defesa dos indivíduos, tornando-os mais susceptíveis a doenças. O autor enfatizou ainda que raízes de indivíduos sob alagamento exudaram etanol, substância que atrai fungos que, entre outros fatores, são responsáveis pela SMP. No presente trabalho, foi observado que raízes de plantas em estádio avançado da SMP eram mais curtas que as de indivíduos tidos como 
saudáveis, o que pode ser decorrente do ambiente em que estas plantas estavam inseridas, solo raso com cascalho a profundidade média de $20 \mathrm{~cm}$.

A partir de seç̧ões transversais, foi observada epiderme uniestratificada, com células de paredes pouco espessadas (Figs. 1 e 2), não havendo alterações anatômicas nem diferença estatística significativa para o tamanho desta camada entre os estádios da SMP (Tab. 1).

A epiderme das raízes de $U$. brizantha analisadas, apesar de apresentar células justapostas, não contem paredes espessadas, característica também exposta por Baruch e Mérida (1995) para o gênero. A mesma é permeável o suficiente em muitos membros da família Poaceae permitindo a entrada de fungos endomicorrízicos capazes de atuar em relação de simbiose, aumentando a produtividade de forrageiras (Taiz \& Zeiger 2013 ).

A região do córtex logo abaixo da epiderme apresentou duas ou três camadas de células da exoderme com paredes celulares mais espessas, provavelmente lignificadas (Figs. 1 e 2), assim como o encontrado por Baruch e Mérida (1995) para Urochloa mutica. A exoderme pluriestratificada de $U$. brizantha exibiu diminuição da espessura com o avanço da SMP (Fig. 2). Pereira et al. (2008), analisando raízes de milho (Zea mays L.) cv. Saracura, observaram diminuição da exoderme ao passo que se aumentava o encharcamento do solo. A SMP é associada por Dias-Filho (2006), ao excesso de água no solo e a resposta fisiológica da planta a esse estresse.

No córtex radical de plantas saudáveis, o parênquima subsequente à camada lignificada se mostrou organizado, apresentando células esféricas de paredes delgadas, dispostas em camadas em direção ao centro da raiz (Fig. 1). Com a evolução da SMP, essa região aparentou gradativa desorganização com surgimento de lacunas geradas pela lise celular (Fig. 2), o que em alguns casos provocou alterações na forma, predominantemente circular das raízes.

A lise celular parece formar aerênquima lisígeno em várias amostras em estádio avançado da SMP. Ramos et al. (2012), relataram o surgimento de aerênquima em raízes de $U$. brizantha abastecidas com altos níveis de selênio. Pereira et al. (2008), afirmaram que o córtex é a região mais sensível da raiz a alterações do ambiente, corroborando com os resultados aqui citados.

$\mathrm{Na}$ espécie em estudo, as paredes anticlinais e periclinal interna das células da endoderme apresentaramse espessadas e menores em relação às demais células do córtex (Fig. 3). Esse espessamento é menor com a evolução da SMP, tornando-se perceptível apenas na parede periclinal interna em estádios mais avançados (Fig. 4). O espessamento de parede de algumas camadas da raiz ocorre por acúmulo de suberina e lignina (Baruch \& Mérida 1995), sendo a endoderme composta de uma linha de células em forma de barril estreitamente justapostas (Dwari \& Mondal 2011).

O pouco espessamento das paredes celulares, observado na endoderme de $U$. brizantha nos estádios finais da SMP, pode ocorrer devido ao consumo de polissacarídeos, gerado pela redução da absorção de nutrientes pela planta e consequente redução da produção fotossintética. Tal hipótese também foi comentada por Rodella \& MaimoniRodella (1992), mencionando que a diminuição de tecidos fotossintetizantes pode gerar menor produção de fibras e polissacarídeos.

Os indivíduos analisados apresentaram cordões de fibras pericíclicas dispostos em duas ou três camadas, envolvendo os tecidos vasculares (Fig. 3). Esta região não apresentou diferenças anatômicas entre os estádios da SMP. Internamente ao periciclo, estão dispostos os grupos de floema, normalmente funcionais em plantas saudáveis. Em estádio mais avançado da SMP ocorreu lise de células do floema (Fig. 4).

Alguns elementos do xilema apresentaram a mesma característica observada nas células do floema (Fig. 4), com aparente lise ou diminuição da espessura da parede celular. No centro do cilindro vascular foi verificada a presença de parênquima medular em formas variadas, composto de células pequenas de parede celular delgada (Fig. 3). Com a evolução da SMP as células da medula sofreram colapso (Fig. 4). Alguns elementos de vasos, assim como a região do centro do cilindro vascular encontravam-se obstruídos (Fig. 5).

Urochloa brizantha não apresentou variações na espessura dos vasos do xilema ou metaxilema entre plantas saudáveis e plantas debilitadas pela SMP, o que pode ser decorrente da sua intolerância ao alagamento, diferente do ocorrido com Zea mays L., estudada por Pereira et al. (2008), que se adaptou a solos encharcados. Sob condições de hipoxia radical Z. mays exibiu diminuição do diâmetro de vasos xilemáticos e da proporção de tecidos de parênquima medular, mas os autores não fizeram observações de substâncias obstruindo os dutos ou lise da medula parenquimática.

As folhas da cultivar analisada exibiram pilosidade em ambas as faces da epiderme, com maior proporção de tricomas na face adaxial. Indivíduos em estádio avançado da SMP apresentaram visualmente menor proporção de tricomas por área foliar. A presença de tricomas tectores é comum em gramíneas (Metcalfe \& Chalk 1960). Essas estruturas também foram encontradas em grande quantidade em Urochloa decumbens Stapf (Nicolau et al. 2010).

Em secção paradérmica, Urochloa brizantha exibiu células epidérmicas com paredes anticlinais sinuosas. Entre as células longas da epiderme estavam presentes células intercostais curtas, silificadas, contendo corpos de sílica ou fitólitos, corroborando Ellis (1979). Estas células apresentaram formas e tamanhos variados (Figs. 6-9), não diferindo entre os estádios da SMP.

Em secção transversal, foi observada cutícula espessa sobre epiderme uniestratificada. A epiderme é composta de células elipsoides de paredes levemente espessadas nas faces anticlinais e periclinais externas (Figs. 10,11). Nicolau et al. (2010) afirmam que paredes anticlinais sinuosas nas células epidérmicas, somados a cutícula espessa podem aumentar a compactação do tecido de revestimento, assegurando 

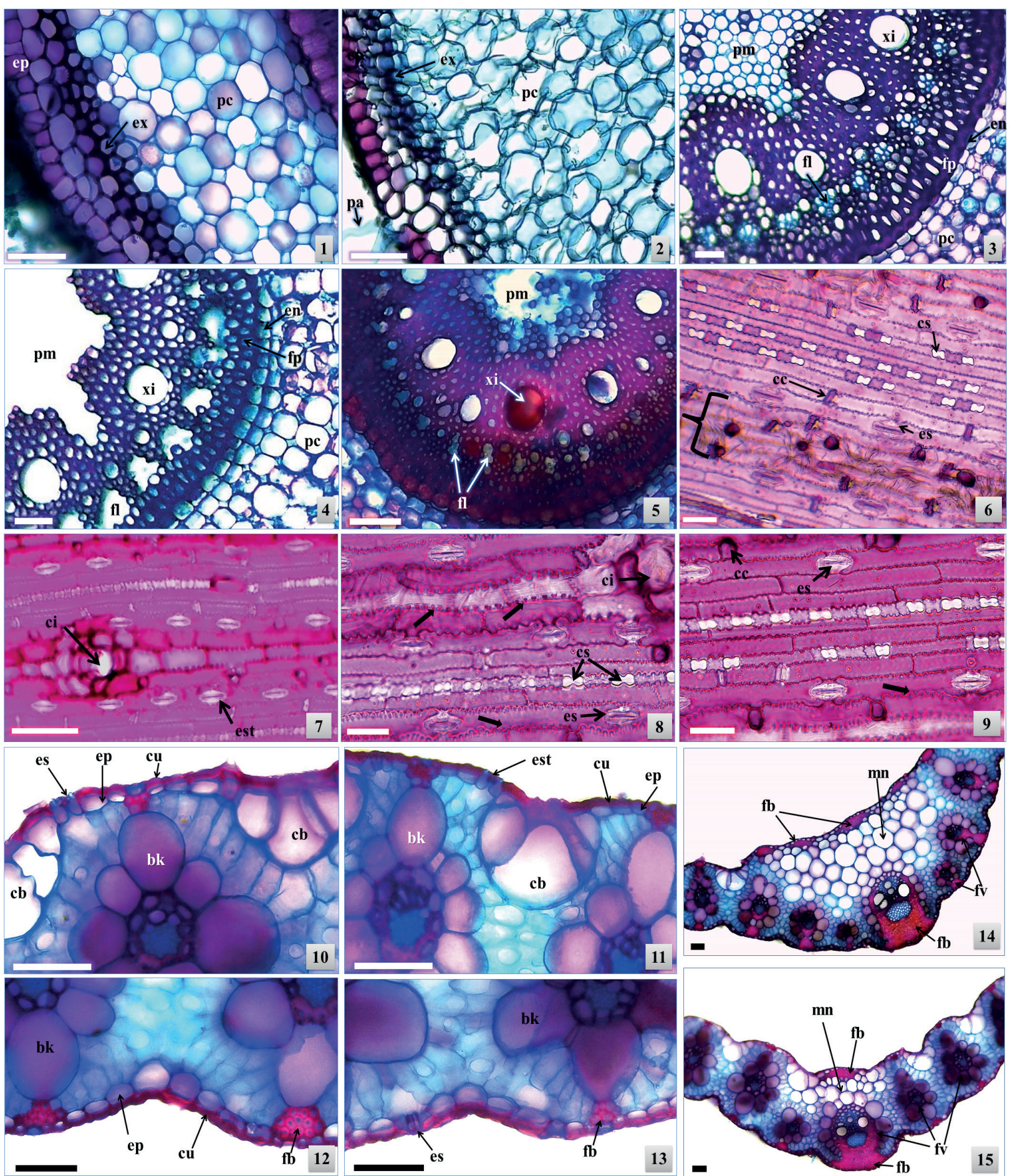

Figs. 1-15. Secções transversais e paradérmicas de Urochloa brizantha cv. Marandu. 1,3-Secções transversais de raízes saudáveis; 2, 4, 5. Secções transversais de raízes acometidas pela síndrome da morte das pastagens (SMP) [estádio 3]; 6. Secção paradérmica da face abaxial da folha; 7-9. Secções paradérmicas da face adaxial da folha [estádio 1, 2 e 3, respectivamente]; 10, 12, 14. Secções transversais das folhas de indivíduos saudáveis; 11, 13, 15. Secções transversais das folhas de indivíduos acometidos pela síndrome da morte das pastagens [estádio 3]. Bainha parenquimática (bk), células buliformes (cb), células curtas (cc), células silicosas (cs), cutícula (cu), cicatriz de tricoma (ci), endoderme (en), epiderme (ep), exoderme (ex), fibras pericíclicas (fp), estômatos (es), fibras esclerenquimáticas (fb), floema (fl), feixe vascular (fv), mesofilo da nervura central (mn), pelo absorvente (pa), parênquima cortical (pc), parênquima medular (pm), xilema (xi), paredes anticlinais sinuosas (seta larga), área sobre feixe vascular (chave). Barras $=50 \mu \mathrm{m}$. 
o sucesso das populações sob estresse hídrico. Foram observadas, em algumas regiões da epiderme, células na face abaxial com menor volume e paredes celulares mais delgadas em estádios mais avançados da SMP (Figs. 12, 13). Não foram encontrados na literatura comentários sobre doenças que possam causar tais alterações. Goulart (2008), ao estudar acessos de Brachiaria, comenta que podem haver diferenças da espessura desse tecido e que variações na parede podem ser decorrentes do metabolismo de determinados cultivares. $\mathrm{O}$ que nos permite inferir que alterações metabólicas decorrentes da SMP geram tais variações.

Plantas debilitadas por doenças ou sob pressões ambientais podem ter sua produção fotossintética comprometida (Silva et al. 2005) ou mesmo direcionar substâncias para a manutenção das funções fisiológicas, diminuindo o acúmulo de polissacarídeos e fibras (Taiz \& Zeiger 2013). Situação também observada em outras onze forrageiras cultivadas com reduzida incidência solar (Soares et al. 2009). O agravamento da SMP em $U$. brizantha, aparentemente gerou alterações metabólicas que resultaram em alterações histológicas similares às citadas, o que pode ser decorrente da absorção de nutrientes e produção fotossintética reduzidas destas plantas.

O aumento do tamanho das células buliformes visualizado com a evolução da SMP na face adaxial não foi significativo estatisticamente (Tab. 2). Estas células mantiveram-se dispostas em grupos regulares e bem definidos de 3 a 5 células, organizadas em forma de leque com a célula central maior (Figs. 10, 11). Em plantas saudáveis, ocorreram em nível ligeiramente abaixo das demais células epidérmicas, formando sulcos. Em plantas em estádio mais avançado da SMP, foram comumente encontradas também em nível levemente acima das demais células epidérmicas, mostrando-se proeminentes.
As células buliformes apresentaram paredes mais delgadas que as demais células epidérmicas, provavelmente composição química diferente, característica esta, confirmada pela dupla coloração (azul de astra + fucsina básica) utilizada por Brito \& Rodella (2002). Nicolau et al. (2010) caracterizaram estas células como motoras, sendo responsáveis pelo enrolamento e/ou dobramento das folhas em condições ambientais adversas. A característica para plantas em estádio avançado da SMP pode justificar a forma como folhas mortas ou amareladas são encontradas, completamente abertas de uma extremidade a outra do limbo, indicando possível perda de funcionalidade das células buliformes.

$\mathrm{Na}$ região da nervura central, o mesofilo foliar apresentou parênquima localizado na porção adaxial, formado por células arredondadas em secção transversal, e desprovidas de cloroplastos. Brito \& Rodella (2002), verificaram que $U$. brizantha apresentou 5 camadas de células de parênquima de preenchimento na região de quilha, quantidade também visualizada no presente trabalho em plantas que não aparentaram acometimento a SMP (Fig. 14).

Foi observada menor quantidade de células na região de quilha com o avanço da SMP, com diferença significativa do diâmetro da quilha entre os estádios morfológicos analisados (Tab. 2), sendo registrada nervura central com espessura similar à do limbo foliar em algumas amostras (Fig. 15). Taiz \& Zeiger (2013) afirmam que plantas sensíveis à inundação são severamente danificadas em 24 horas de anoxia, pois esse estresse altera as trocas gasosas, sendo capaz de diminuir as divisões celulares, responsáveis pela reposição celular da planta.

Extensões de bainha compostas por agrupamentos de células esclerenquimáticas de parede notadamente espessadas ocorreram nas duas faces da folha, ligando os

Tabela 1. Morfometria do terço médio de raízes de Urochloa brizantha em 3 estádios morfológicos da síndrome da morte das pastagens (SMP). Estádios: 1 plantas saudáveis, 2 plantas em início da SMP, 3 plantas em estádio avançado de SMP. Tamanho da epiderme (EPI), diâmetro da raiz (DIAM), diâmetro cilindro vascular (DIAM cilin), número de polos de protoxilema (PROTOX), coeficiente de variação (CV), diferença mínima significativa (DMS). Letras iguais na coluna não diferem significativamente $(\mathrm{p}<0,05)$, segundo o teste de Tukey.

\begin{tabular}{lcccc}
\hline Estádios & EPI $(\mu \mathrm{m})$ & DIAM $(\mu \mathrm{m})$ & DIAM cilin $(\mu \mathrm{m})$ & PROTOX \\
\hline $\mathbf{1}$ & $26,54 \mathrm{a}$ & $1489,37 \mathrm{a}$ & $791,99 \mathrm{a}$ & $35,00 \mathrm{a}$ \\
$\mathbf{2}$ & $26,27 \mathrm{a}$ & $1568,77 \mathrm{a}$ & $850,22 \mathrm{a}$ & $32,41 \mathrm{a}$ \\
$\mathbf{3}$ & $23,30 \mathrm{a}$ & $1489,37 \mathrm{a}$ & $791,99 \mathrm{a}$ & $36,41 \mathrm{a}$ \\
CV $(\%)$ & 23,75 & 21,10 & 22,03 & 16,77 \\
DMS & 6,03 & 341,31 & 187,26 & 5,81 \\
\hline
\end{tabular}

Tabela 2. Morfometria do terço médio de folhas de Urochloa brizantha em 3 estádios morfológicos da síndrome da morte das pastagens (SMP). Estádios: 1 plantas saudáveis, 2 plantas em início da SMP, 3 plantas em estádio avançado de SMP. Nervura central (NC), células buliformes (C B), fibras abaxiais (F ABA), fibras adaxiais (F ADA), mesofilo da lâmina foliar (MES), coeficiente de variação (CV), diferença mínima significativa (DMS). Letras iguais na coluna não diferem significativamente a $(\mathrm{p}<0,05)$, segundo o teste de Tukey.

\begin{tabular}{lccccc}
\hline Estádio & NC $(\mu \mathrm{m})$ & $\mathrm{C} \mathrm{B}(\mu \mathrm{m})$ & F ABA $(\mu \mathrm{m})$ & F ADA $(\mu \mathrm{m})$ & MES $(\mu \mathrm{m})$ \\
\hline $\mathbf{1}$ & $490,58 \mathrm{a}$ & $71,94 \mathrm{a}$ & $99,18 \mathrm{a}$ & $45,38 \mathrm{a}$ & $209,95 \mathrm{a}$ \\
$\mathbf{2}$ & $410,91 \mathrm{~b}$ & $81,29 \mathrm{a}$ & $91,18 \mathrm{ab}$ & $43,18 \mathrm{ab}$ & $209,94 \mathrm{a}$ \\
$\mathbf{3}$ & $342,48 \mathrm{c}$ & $86,52 \mathrm{a}$ & $77,36 \mathrm{~b}$ & $35,40 \mathrm{~b}$ & $209,54 \mathrm{a}$ \\
CV (\%) & 14,24 & 25,04 & 16,36 & 20,71 & 14,90 \\
DMS & 59,16 & 20,05 & 14,63 & 8,57 & 31,33 \\
\hline
\end{tabular}


feixes vasculares à epiderme no limbo foliar e ligando o feixe vascular central a epiderme abaxial (Figs. 10-13). Em estádio mais avançado da SMP foram observadas menores proporções de fibras ao longo do órgão (Tab. 2). Variações ambientais podem causar diminuição nas quantidades de tecido vascular e de sustentação (Gobbi et al. 2011), o que corrobora com o observado em $U$. brizantha e Panicum maximum Jacq. onde a diminuição das taxas fotossintéticas provocou diminuição da produção de massa seca (Soares et al. 2009). A diminuição da produção fotossintética pode ter causado a diminuição das calotas de fibras registradas no presente estudo.

Como a maioria das gramíneas tropicais com via fotossintética C4, U. brizantha apresentou anatomia Kranz., onde as células do parênquima clorofiliano dispõem-se radialmente ao redor dos feixes. Internamente a coroa de células do mesofilo, foi visualizada a bainha parenquimática do feixe vascular, com uma camada de células como o descrito por Metcalfe \& Chalk (1960) para Urochloa.

As plantas em estádio mais avançado da SMP exibiram tecidos radicais degradados, sobretudo os tecidos não lignificados, obliteração das células dos tecidos condutores, paredes da exoderme e endoderme mais delgadas, o que as tornam mais susceptíveis a patógenos. Nas folhas, ocorreu a diminuição de tricomas, além de menores proporções de fibras esclerenquimáticas e parênquima fundamental do mesofilo na nervura central no estádio mais avançado da SMP, que são prováveis respostas à deterioração dos tecidos radicais.

\section{AGRADECIMENTOS}

Agradecemos a Coordenação de Aperfeiçoamento de Pessoal de Nível Superior (CAPES) e a Fundação de Amparo à Pesquisa de Mato Grosso (FAPEMAT) pela concessão de bolsa ao primeiro e terceiro autor.

\section{REFERÊNCIAS}

Aguiar, T.V., Sant'anna-Santos, B.F., Azevedo, A.A. \& Ferreira, R.S. 2007. Anati Quanti: software de análises quantitativas para estudos em anatomia vegetal. Planta Daninha 25(4): 649-659.

Baruch, Z. \& Mérida, T. 1995. Effects of drought and flooding on root anatomy in four tropical forage grasses. International Journal of Plant Sciences 156(4): 514-521.

Brito, C.J.F.A. \& Rodella, R. A. 2002. Caracterização morfo-anatômica da folha e do caule de Brachiaria brizantha (Hochst. ex A. Rich.) Stapf e B. humidicola (Rendle) Schweick. (Poaceae). Revista Brasileira de Botânica 25(2): 221-228.
Da Silva, S.C. \& Nascimento Júnior, D. 2007. Avanços na pesquisa com plantas forrageiras tropicais em pastagens: características morfofisiológicas e manejo do pastejo. Revista Brasileira de Zootecnia 36: $121-138$.

Dias-Filho, M.B. 2006. Respostas morfofisiológicas de Brachiaria spp. ao alagamento do solo e síndrome da morte do capim-marandu. In Morte de pastos de Braquiárias (R.A. Barbosa, ed.). Embrapa Gado de Corte, Campo Grande, p. 83-101.

Dwari, S. \& Mondal, A. K. 2011. Systematic studies (morphology, anatomy and palynology) of economically viable grass Brachiaria mutica (Forsskil) Stapf in Eastern India. African Journal of Plant Science 5(5): 296-304.

Ellis, R.P. 1979. A procedure for standardizing comparative leaf anatomy in the Poaceae. The epidermis as seen in surface view. Bothalia 12(4): 641-671.

Ferreira, D.F. 2011. Sisvar: a computer statistical analysis system. Ciência e Agrotecnologia 35(6): 1039-1042.

Gobbi, K.F., Garcia, R., Ventrella, M.C., Garcez Neto, A.F. \& Rocha, G.C. 2011.Área foliar específica e anatomia foliar quantitativa do capimbraquiária e do amendoim-forrageiro submetidos a sombreamento. Revista Brasileira de Zootecnia 40: 1436-1444.

Goulart, J.C. 2008. Citogenética e anatomia foliar de acessos e progênies de Brachiaria. Dissertação 71 f. Universidade Federal de Lavras, Lavras.

Johansen, D.A. 1940. Plant microtechnique. McGraw-Hill Book Inc., New York. 523 p.

Kraus, J.E. \& Arduin, M. 1997. Manual básico de métodos em morfologia vegetal. Editora Universidade Rural, Rio de Janeiro. 198 p.

Metcalfe, C.R. \& Chalk, L. 1960. Anatomy of monocotyledons. Gramineae. Clarendon Press, Oxford, v.1.731 p.

Nicolau, B.A.P., Alvarenga, T.M., Fonseca, F. \& Júnior, F.J.S. 2010. Morfoanatomia foliar de Brachiaria decumbens Stapf, coletada na zona rural de Lavras, estado de Minas Gerais, Brasil. Revista Científica UDO Agrícola 10(1): 1-6.

Pereira, F.J., Castro, E.D., Souza, T., D. \& Magalhães, P.C. 2008. Evolução da anatomia radicular do milho 'Saracura' em ciclos de seleção sucessivos. Pesquisa Agropecuária Brasileira 43(12): 1649-1656.

Ramos, S.J., Avila, F.W., Boldrin, P.F., Pereira, F.J., Castro, E.M., Faquin, V. \& Guilherme, L.R.G. 2012. Response of Brachiaria grass to selenium forms applied in a tropical soil. Plant, Soil and Environment 58(1): 521-527.

Rodella, R.A. \& Maimoni-Rodella, R.C.S. 1992. Estudo quantitativo da anatomia foliar e caulinar de duas espécies daninhas de Ipomoea. Revista de Agricultura 67(1): 35-48.

Roeser, K.R. 1962. Die nadel der schwarzkiefer-massenprodukt und kunstwerk der natur. Microkosmos 61: 33-36.

Secretaria de Estado de Planejamento e Coordenação Geral - SEPLAN. 2006. Unidades Climáticas do Estado de Mato Grosso. Disponível em: http://www.dados.mt.gov.br/publicacoes/dsee/climatologia/rt/ DSEE-CL-RT-002-A021.pdf. Acessado em 12.06.2015.

Silva, L.M., Alquini, Y. \& Cavallet, V.J. 2005. Inter-relações entre a anatomia vegetal e a produção vegetal. Acta Botanica Brasilica 19(1): 83-194.

Soares, A.B., Sartor, L.R., Adami, P.F., Varella, A.C., Fonseca, L. \& Mezzalira, J.C. 2009. Influência da luminosidade no comportamento de onze espécies forrageiras perenes de verão. Revista Brasileira de Zootecnia 38(3): 443-451.

Taiz, L. \& Zeiger, E. 2013. Fisiologia vegetal. Artmed, Porto Alegre. 954 p. 